\title{
Waterborne nickel bioaccumulation in Gammarus pulex: Comparison of mechanistic models and influence of water cationic composition
}

\author{
Jérémie D. Lebrun $^{\mathrm{a}, \mathrm{b}, *}$, Marine Perret ${ }^{\mathrm{a}, \mathrm{b}}$, Emmanuelle Uher $^{\mathrm{a}, \mathrm{b}}$, Marie-Hélène Tusseau-Vuillemin ${ }^{\mathrm{c}}$, \\ Catherine Gourlay-Francé ${ }^{a, b}$
}

\author{
${ }^{a}$ CEMAGREF, Unité HBAN, Parc de Tourvoie, 92163 Antony cedex, France \\ ${ }^{\mathrm{b}}$ FIRE FR-3020, 4 place Jussieu, 75005 Paris, France \\ c IFREMER, 155 rue Jean-Jacques Rousseau, 92138 Issy-Les-Moulineaux, France \\ *: Corresponding author : Jérémie D. Lebrun, Tel.: +330140 966539 ; fax: +33 0140966199 ;
email address : jeremie.lebrun@cemagref.fr
}

\begin{abstract}
:
The biodynamic and saturation models offer promising lines of enquiry to predict the bioaccumulation of metals by aquatic organisms. However, in order to construct these models, the accumulation strategies have to be defined for each metal/organism couple in controlled conditions. This study aims at modelling the waterborne bioaccumulation of $\mathrm{Ni}$ and the influence of the water's geochemical properties on this process in a crustacean that is widely distributed in Europe, Gammarus pulex. In the laboratory, G. pulex was exposed to several Ni concentrations (from 0.001 to $100 \mathrm{mg} \mathrm{L}^{-1}$ ) in aquatic microcosms. Our results show that $G$. pulex is very tolerant to $\mathrm{Ni}\left(\mathrm{LC} \mathrm{O}_{48 \mathrm{~h}}=477 \mathrm{mg} \mathrm{L}^{-1} \mathrm{Ni}\right)$. Time course experiments enabled the construction of a biodynamic model by determining the uptake $\left(k_{u}\right)$ and elimination $\left(k_{e}\right)$ rate constants. When the exposure concentration exceeded $1 \mathrm{mg} \mathrm{L}^{-1} \mathrm{Ni}$, the metal uptake reached a maximum due to a limited number of binding sites for Ni. Therefore, the organism's maximal capacity to accumulate the metal $\left(B_{\max }\right)$ and the half-saturation constant $(K)$ were determined to establish the saturation model. We showed that the two models are comparable for the lowest exposure concentrations $\left(<1 \mathrm{mg} \mathrm{L}^{-1} \mathrm{Ni}\right)$, with $k_{u} / k_{e}=B_{\max } / \mathrm{K}$. Then, the bioaccumulation of $\mathrm{Ni}$ was recorded in waters exhibiting various concentrations of three major ions $\left(\mathrm{Na}^{+}, \mathrm{Mg}^{2+}\right.$ and $\left.\mathrm{Ca}^{2+}\right)$. Only $\mathrm{Ca}$ had an inhibitory effect on the Ni uptake. This study reports for the first time the bioaccumulation of $\mathrm{Ni}$ in G. pulex. Because of its high tolerance to $\mathrm{Ni}$ and its high capacity to accumulate this metal, this crustacean could be used as an indicator of $\mathrm{Ni}$ bioavailability in freshwaters.
\end{abstract}

Keywords: Biodynamic kinetics ; Saturation model ; Gammarid ; Bioavailability ; Water chemistry ; Aquatic microcosms 


\section{Introduction}

Although metals are naturally released by geochemical sources in freshwaters, human activities result in an overproduction of these contaminants and cause a change in their speciation, which are found in more mobile chemical forms. This speciation controls their distribution in the environmental components. Chemical analyses enable the determination of the total concentrations of dissolved or particulate metals in waters but, they do not give information about the bioavailability of metals that is potentially toxic for aquatic organisms. Moreover, metal bioavailability is strongly affected by water chemistry. Consequently, the usual analyses are insufficient to assess the impact of metals on environmental health. An alternative approach to evaluate the bioavailable contamination in freshwaters is to determine the contamination in biota, since it integrates both the metal exposures of biological organisms and the effects of the water's geochemistry on bioavailability (McGeer et al., 2003; Rainbow, 2007). Thus, metal bioaccumulation regarded as an integrative indicator offers promising lines of enquiry as regards the quality assessment of freshwaters.

Nickel $(\mathrm{Ni})$ is one of the priority substances singled out by the European Water Framework Directive for the protection of aquatic ecosystems (Directive 2008/105/EC). Indeed, this metal is a common contaminant in freshwaters because of its industrial and domestic applications, with potential ecological consequences (Ponton and Hare, 2010). Ni concentrations can exceed $1 \mathrm{mg} \mathrm{L}^{-1}$ in freshwaters near industrial or mining sites, whereas the average value in uncontaminated rivers worldwide is around $0.001 \mathrm{mg} \mathrm{L}^{-1} \mathrm{Ni}$ (Gaillardet et al., 2004; Kienle et al., 2009). Since the link between the medium's contamination and bioaccumulation is not straightforward, the mechanisms involved in accumulation processes and the influence of water chemistry on these processes have to be defined for each metal/organism couple in controlled conditions. Nevertheless, the bioaccumulation data for $\mathrm{Ni}$ is far less extensive than for other metals such as $\mathrm{Zn}$, Cu or $\mathrm{Cd}$, whose bioaccumulation has been reported in various aquatic species (Buchwalter and Luoma, 2005; Croteau and Luoma, 2007; Ferreira et al., 2009).

Benthic macroinvertebrates are especially suitable to monitor metal contamination levels in freshwaters because of their sedentary life-cycle (Rainbow, 2002; Clason et al., 2004). Among these biomonitors, interest has recently focused on amphipods because they are net accumulators of many metals. Efficient accumulations of metals, essential or not, have been reported in Hyalella azteca or in Gammarideans such as Gammarus pulex or G. fossarum (Borgmann et al., 2004; Norwood et al., 2006; Felten et al., 2008; Geffard et al., 2010). Although amphipods are rather resistant to metals with respect to acute toxicity, metal accumulations can induce sublethal alterations at the physiological, behavioural or biochemical level (Besser et al., 2005; Felten et al., 2008; Debourge-Geffard et al., 2009). Gammarids are therefore used for the development of biomarkers of metal exposure. Furthermore, amphipods are widely distributed in aquatic ecosystems and are key components of their functioning. They contribute to nutrient cycles by decaying organic matter and are an important food source for fish or bird species. Because amphipods are both ecologically important and relatively resistant to metals, they are interesting candidates to quantify the fraction of bioavailable metals in the environment.

Among different bioaccumulation models proposed in the literature, the biodynamic model is one of the most commonly used for aquatic animals. This model predicts that the net bioaccumulation is the result of a balance between the uptake of dissolved metals and the uptake from diet on the one hand, and the efflux of bioaccumulated metals by excretion and by biodilution due to growth on the other hand (Luoma and Rainbow, 2005). It has been shown to be well suited to several species of molluscs, crustaceans or fish (Liu et al., 2002; Rainbow, 2007; Pellet et al., 2009). During waterborne exposures in the laboratory, metal fluxes depend on kinetic parameters, i.e. the uptake and depuration rates, which are assumed to be constant over a wide range of metal concentrations in water according to the biodynamic 
model. These kinetic parameters are specific to each metal/organism couple. Nevertheless, it is possible that the metal uptake saturates for high exposures due to a limited number of specific binding sites within the organism (Borgmann et al., 2004; Norwood et al., 2006). The metal bioaccumulation is then alternatively described using a saturation model as has been done for the amphipod Hyalella azteca, the snail Lymnea stagnalis or aquatic microorganisms (Borgmann et al., 2004; Worms et al., 2006; Croteau and Luoma, 2007). Although the biodynamic and saturation models coexist in the literature, their predictions of bioaccumulation for the same organism are rarely compared.

In the literature, the major metal forms suggested as bioavailable are free ions, which can directly interact with transport sites on the biological membranes of aquatic organisms (Niyogi and Wood, 2004). Competitions for physiological binding sites may occur between free metals and major ions found in freshwaters such as $\mathrm{Na}, \mathrm{Mg}$ or $\mathrm{Ca}$, leading to a decrease in the bioavailability and therefore, in the metal uptake. For example, increasing concentrations of $\mathrm{Ca}$ inhibit the waterborne Cd uptake in G. pulex, the crustacean Daphnia magna and the mussel Dreissena polymorpha (Komjarova and Blust, 2009; Pellet et al., 2009; Bourgeault et al., 2010). Such an inhibitory effect of $\mathrm{Ca}$ on $\mathrm{Ni}$ uptake has been proposed to explain the decrease in the metal's toxicity in Daphnia pulex and in Ceriodaphnia dubia (Keithly et al., 2004; Kozlova et al., 2009). These modulations of metal uptake highlight the necessity of integrating the water chemistry into bioaccumulation models in order to improve their calculations.

Despite the environmental concerns caused by $\mathrm{Ni}$, few studies have investigated the accumulation processes of this metal in aquatic animals. This study aims at modelling the waterborne bioaccumulation of $\mathrm{Ni}$ and the influence of the water's geochemical properties on this process in a crustacean that is widely distributed in Europe, Gammarus pulex. In the laboratory, the organism was exposed to several concentrations of $\mathrm{Ni}$ (from 0.001 to $100 \mathrm{mg}$ $\mathrm{L}^{-1}$ ) in aquatic microcosms, so as to establish kinetic constants and binding characteristics for the construction of biodynamic and saturation models. Then, the Ni uptake was recorded in waters exhibiting various concentrations of three major cations at environmental levels $\left(\mathrm{Na}^{+}\right.$, $\mathrm{Mg}^{2+}$ and $\mathrm{Ca}^{2+}$ ), in order to construct bioaccumulation models that take into account the influence of these geochemical parameters.

\section{Theory}

\subsection{Biodynamic kinetics of dissolved metal uptake and elimination}

According to the biodynamic model, metal concentrations in an organism result from a balance of unidirectional fluxes over the time. Assuming that the organism's growth is negligible during short-time exposures, the waterborne bioaccumulation of metal is therefore described by first-order kinetic models (Clason et al., 2004; Luoma and Rainbow, 2005):

$$
\frac{d C_{a}}{d t}=k_{u} C_{w}-k_{e} C_{a}
$$

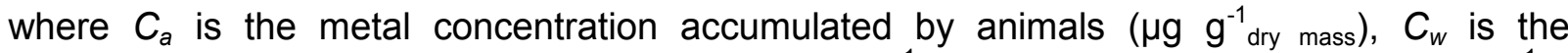
concentration of bioavailable metal in the water $\left(\mu \mathrm{g} \mathrm{L}^{-1}\right), k_{u}$ is the uptake rate constant $\left(\mathrm{L} \mathrm{g}^{-1}\right.$ dry mass $\left.\mathrm{d}^{-1}\right)$ and $k_{e}$ is the elimination rate constant $\left(\mathrm{d}^{-1}\right)$. In this model, the rate constants are specific to each metal/organism couple and do not vary with the metal concentrations in water (Luoma and Rainbow, 2005).

When initially uncontaminated gammarids are exposed to a constant metal concentration in water, the integration of Eq. 1 characterizes metal accumulation as follows: 


$$
C_{a}=\frac{k_{u} C_{w}}{k_{e}}\left(1-\exp \left(-k_{e} t\right)\right)
$$

Assuming the metal elimination is negligible at the beginning of the exposure, Eq. 1 can be simplified as follows:

$$
I=k_{u} C_{w}
$$

where $I=d C_{d} / d t_{\leq 24 h}$ is the initial metal influx $\left(\mu \mathrm{g} \mathrm{g}^{-1}\right.$ dry mass $\left.\mathrm{d}^{-1}\right)$.

When contaminated gammarids are introduced into uncontaminated water (where $C_{w}=0$ ), metal elimination is then defined by Eq. 4:

$$
C_{a}=C_{a o} \exp \left(-k_{e} t\right)
$$

where $C_{a o}$ is the Ni concentration in animals at the start of the depuration phase.

Finally, the waterborne bioaccumulation of metals at the steady state $(t \rightarrow \infty)$ is described by the biodynamic model as follows:

(5) $\quad C_{s s}=\frac{k_{u} C_{w}}{k_{e}}$

where $C_{s s}$ is the amount of metal in animals at the steady state $\left(\mu \mathrm{g} \mathrm{g}^{-1}\right.$ dry mass $)$.

\subsection{Saturation of metal uptake and analogical modelling}

The initial influx reflects the processes involved in the transport across a biological membrane due to the affinity of the metal for specific binding sites. According to the biodynamic model, $I$ is proportional to the metal concentration in water which suggests that binding sites are not limited. By contrast, a saturation model relying on principles derived from enzyme kinetics considers that the number of binding sites becomes limited at high exposure concentrations (Croteau and Luoma, 2007). Therefore, the influx reaches a maximum and the metal uptake tends to saturate. This process is described by the Michealis-Menten equation, which defines a saturation curve (Borgmann et al., 2004; Worms et al., 2006), with

(6) $\quad I=\frac{I_{\max } C_{w}}{K+C_{w}}$

where $I_{\max }$ is the maximal influx and $K$ is the half-saturation constant $\left(\mu \mathrm{g} \mathrm{L}^{-1}\right)$.

Hence, in this model, the uptake rate constant $k_{u}$ depends on the exposure concentration:

$$
k_{u}=\frac{I_{\max }}{K+C_{w}}
$$

Combining Eqs. 5 and 7, we obtain the Eq. 8 which describes the metal concentration in animals at the steady state as suggested by Norwood et al. (2006), with $I_{\max }=B_{\max } k_{e}$ 


$$
C_{s s}=\frac{B_{\max } C_{w}}{K+C_{w}}
$$

where $B_{\max }$ is the maximal capacity of an animal to bind the metal at the specific sites $\left(\mu \mathrm{g} \mathrm{g}^{-1}\right.$ mass).

\section{Materials and Methods}

\subsection{Collection and maintenance of Gammarus pulex}

Adult G. pulex were collected in May and June 2010 in a river characterized by relatively minor metal contamination ( $R u$ de l'Etang, Doue, France), insofar as the dissolved concentrations for several metals were overall inferior to world average values in uncontaminated rivers (Gaillardet et al., 2003). Gammarids were selected using a series of sieves: we only kept those that passed through a $2.5 \mathrm{~mm}$, but not a $2 \mathrm{~mm}$ sieve. They were then acclimated for 7-10 d in aquaria containing aerated Volvic ${ }^{\circledR}$ mineral water $\left(\mathrm{Ca}^{2+} 11.5, \mathrm{Na}^{+}\right.$ 11.6, $\mathrm{Mg}^{2+}$ 8.0, $\mathrm{K}^{+} 6.2, \mathrm{Cl}^{-} 13.5$ and $\mathrm{SO}_{4}{ }^{2+} 8.1 \mathrm{mg} \mathrm{L}^{-1} ; \mathrm{pH}$ 7). This mineral water was chosen for its low cationic composition, so that the influence of cation additions on metal uptake could later be assessed. Aquaria were maintained at $14^{\circ} \mathrm{C}$ under a 12:12-h light:dark photoperiod. Amphipods were fed ad libitum with alder leaves (Alnus glutinosa).

\subsection{Experimental procedures and LC50}

Aquatic microcosms were fashioned with beakers containing $500 \mathrm{~mL}$ of Volvic mineral water spiked with $\mathrm{NiSO}_{4} \cdot 6 \mathrm{H}_{2} \mathrm{O}$ (> 99\% purity, Sigma-Aldrich) at final concentrations of 0.001 , $0.005,0.01,0.1,1,10$ or $100 \mathrm{mg} \mathrm{L}^{-1} \mathrm{Ni}$. The exposure media were previously equilibrated for $24 \mathrm{~h}$ and renewed before exposing gammarids in order to minimize the binding of metal with the system surface and to ensure constant exposure concentrations of $\mathrm{Ni}$. Then, 60 gammarids were placed in each beaker and exposed for $5 \mathrm{~d}$ without food. During the accumulation phase, pools of 5 gammarids were sampled at $0.5,1,2$ and $5 \mathrm{~d}$ for each condition. On the $5^{\text {th }}$ day, the contamination was abruptly stopped by supplying uncontaminated water and amphipods were fed ad libitum with alder leaves. During the depuration phase, pools of 5 gammarids were sampled at $0.5,1,2,4$ and $7 \mathrm{~d}$ for each condition. Before being frozen at $-20^{\circ} \mathrm{C}$, gammarids were rinsed with 2 and $0.5 \mathrm{mM}$ EDTA, then twice with ultrapure waters for $1 \mathrm{~min}$, so as to remove the metal potentially adsorbed on the organisms (Norwood et al., 2006).

The time course experiments were performed in triplicates, i.e. three microcosms for each exposure condition. Exposure media were maintained at $14{ }^{\circ} \mathrm{C}$ under a 12:12-h light:dark photoperiod. They were renewed every day and water samples were taken to control total concentrations of metal added during the exposure. Water samples $(3 \mathrm{~mL})$ were preserved by adding $30 \mu \mathrm{L}$ of concentrated nitric acid. The Ni concentrations measured in water samples ranged from 95 to $99 \%$ of nominal concentrations in waters.

During all exposure experiments, dead animals were removed from microcosms every day, which enabled the generation of the lethal concentration of $\mathrm{Ni}$ leading to $50 \%$ mortality of animals (LC50). In the absence of $\mathrm{Ni}$, the maintenance of gammarids for $14 \mathrm{~d}$ in aquatic microcosms containing Volvic ${ }^{\circledR}$ mineral water led to a mortality rate below $2 \%$. 


\subsection{Effect of $\mathrm{Na}, \mathrm{Mg}$ and $\mathrm{Ca}$ on the uptake rate}

To test the influence of major ions on metal uptake, gammarids were exposed to $100 \mu \mathrm{g}^{-1} \mathrm{Ni}$ in waters spiked with different concentrations of $\mathrm{NaCl}, \mathrm{CaCl}_{2}$ and $\mathrm{MgSO}_{4} \cdot 7 \mathrm{H}_{2} \mathrm{O}(>99 \%$ purity). The cationic solutions were made with the mineral water. As previously described, gammarids were introduced into equilibrated aquatic microcosms containing 20, 40 and $80 \mathrm{mg}$ $\mathrm{L}^{-1}$ of $\mathrm{Na}$ or $\mathrm{Mg}$, or 50,100 and $200 \mathrm{mg} \mathrm{L}^{-1} \mathrm{Ca}$. Pools of 5 gammarids were sampled at 1 and $2 \mathrm{~d}$ for each condition, and were then frozen and mineralized for the determination of $\mathrm{Ni}$ concentrations in animals.

\subsection{Ni concentrations in water and body burden samples}

The frozen amphipod pools were dried at $50^{\circ} \mathrm{C}$ for $3 \mathrm{~d}$ in $50 \mathrm{~mL}$ polypropylene tubes (SCP Science). The determination of dry weights confirmed the assumption that growth is negligible during exposure. Then, dried amphipod pools were digested by adding nitric acid and hydrogen peroxide as described by Pellet et al. (2009). Mineralized samples as well as water samples were analyzed for $\mathrm{Ni}$ using a graphite furnace atomic absorption spectrophotometer with Zeeman background correction (SpectrAA 220Z, Varian). The digestion method was successfully validated by a reference material (Mussel Tissue ERMCE278). Calibrations were performed every 20 samples using a reference water (SPS-SW1).

\subsection{Calculations of parameters for biodynamic and saturation models}

Net accumulations by G. pulex exposed to Ni were determined by substituting the background metal concentration measured in unexposed animals for each sampling time. For each addition of $\mathrm{Ni}$ in waters, the initial influxes $(I)$ were determined for the first $24 \mathrm{~h}$ of waterborne exposure by linear regression of net bioaccumulation against time. The steady state $\mathrm{Ni}$ concentrations in animals $\left(C_{s s}\right)$ and elimination rate constants $\left(k_{e-a c c}\right)$ were calculated by fitting the non-linear regression given in Eq. 2 on the bioaccumulation dataset obtained during the $5 \mathrm{~d}$-accumulation phases. Elimination rate constants $\left(k_{\mathrm{e}-\mathrm{dep}}\right)$ were also calculated from $\mathrm{Ni}$ depuration phases as the slope of the linear regression of $\ln \left(C_{a} / C_{a o}\right)$ against time (Eq. 4).

The uptake rate constant $\left(k_{u}\right)$ was determined from the slope of the linear regression between initial influxes and $\mathrm{Ni}$ concentrations in waters, taking into account only the lowest exposure concentrations for which the metal uptake was linear. The non-linear regression fit of Eq. 6 was performed on the entire initial influx data obtained for all exposure concentrations to determine the half-saturation constant $(K)$ and the saturation point of curve, which reflects the maximal influx $\left(I_{\max }\right)$. The maximal capacity of an animal to bind the metal $\left(B_{\max }\right)$ was calculated as the ratio of $I_{\text {max }} / k_{\text {e-dep }}$.

\subsection{Statistical analyses}

Metal concentrations in animal bodies were expressed as means \pm standard errors (SE) from three independent sets of exposure media and compared to controls through the $t$ test $(p<0.05)$. Linear and non-linear regressions were fitted using XLStat (Addinsoft). Standard errors were reported for biodynamic constants and binding characteristics established by the statistical program. 


\section{Results and Discussions}

\subsection{Toxicity of $\mathrm{Ni}$ in Gammarus pulex}

The Ni concentrations in waters leading to $50 \%$ mortality of gammarids decreased over time, with 24, 48, and $120 \mathrm{~h} \mathrm{LC50}$ values of $1850,477,158 \mathrm{mg} \mathrm{L}^{-1} \mathrm{Ni}$, respectively. A maximal concentration of $100 \mathrm{mg} \mathrm{L}^{-1} \mathrm{Ni}$ was therefore selected to limit the toxicity of Ni for G. pulex during the time course experiments. By comparison, the $\mathrm{LC} \mathrm{O}_{48 \mathrm{~h}}$ value was measured at $0.5 \mathrm{mg} \mathrm{L}^{-1}$ for the toxic metal $\mathrm{Cd}$, and a high mortality has been observed at $1 \mathrm{mg} \mathrm{L}^{-1}$ for the essential metal Zn (Xu and Pascoe, 1993; Felten et al., 2008). The LC50 ${ }_{48 \mathrm{~h}}$ value for Daphnia pulex exposed to $\mathrm{Ni}$ was $0.9 \mathrm{mg} \mathrm{L}^{-1}$ (Kozlova et al., 2009). Our results show that Gammarus pulex has a great tolerance for $\mathrm{Ni}$, confirming the relevance of this organism as a biomonitor of $\mathrm{Ni}$ contamination in freshwaters.

\subsection{Biodynamic parameters established from time course experiments}

A positive background level of $\mathrm{Ni}$ ranging from 0.7 to $1.3 \mu \mathrm{g} \mathrm{g}^{-1}$ dry mass was observed in unexposed G. pulex. By comparison with controls, G. pulex significantly accumulated Ni from a concentration of $5 \mathrm{\mu g} \mathrm{L}^{-1} \mathrm{Ni}$ upwards. Figure 1 depicts an example of time course experiment. During the exposure phase, Ni concentrations in animals increased linearly for the first $24 \mathrm{~h}$ (Eq. 3; $\mathrm{R}^{2}>0.93$ ), followed by a gradual decrease suggesting that a significant $\mathrm{Ni}$ excretion occurred as described by Eq. $2\left(R^{2}>0.88\right)$. During the depuration phase, Ni was exponentially excreted over time (Eq. $4 ; R^{2}>0.92$ ). For each exposure concentration, the initial influxes $(I)$, the steady state concentrations of $\mathrm{Ni}$ in gammarids $\left(C_{s s}\right)$ and the elimination rate constants $\left(k_{e}\right)$ determined through the time courses experiments are given in Table 1.

All $k_{e-a c c}$ and $k_{e-d e p}$ calculated separately from the time courses of accumulation and depuration were in the same order of magnitude which confirmed that the metal elimination rate remains constant regardless of the exposure concentrations, as assumed by the biodynamic model (Luoma and Rainbow, 2005). Moreover, this validated $C_{s s}$ values estimated by the first-order kinetic model (Eq. 2). In the literature, it has been reported that crustaceans can detoxify metals such as $\mathrm{Cu}, \mathrm{Zn}$ or $\mathrm{Cd}$ thanks to the metal-rich granules or vacuoles that are released into the gut lumen during their feeding (Ahearn et al., 2004; Rainbow, 2002). Since the mean values of $k_{e-a c c}$ and $k_{e-d e p}$ are not significantly different (Table 1 ), the fact that gammarids are fed during the depuration phases does not seem to trigger such detoxification mechanisms. Hence, in G. pulex, Ni seems to be easily excreted by simple physiological mechanisms, such as the regulation of ion homeostasis.

The elimination rate constant of $\mathrm{Ni}$ was about 4 times higher than those of $\mathrm{Zn}$ or $\mathrm{Cd}$ in G. pulex (Xu and Pascoe, 1993; Pellet et al., 2009). This may be the result a low sequestration of $\mathrm{Ni}$ by intracellular mechanisms involving high-affinity binding sites or low molecular weight proteins named metallothioneins (Ahearn et al., 2004). Indeed, it is known that essential metals are generally stored by aquatic animals for their metabolic needs, which limits their elimination (Rainbow, 2002). Moreover, in the case of $G$. fossarum, it has been reported that $\mathrm{Cd}$ and $\mathrm{Pb}$ are preferentially internalized in insoluble fractions (i.e. metal-rich granules, cellular membranes or organelles) whereas $\mathrm{Ni}$ is rather found in cytosolic fractions (Geffard et al., 2010). The elimination efficiency of $\mathrm{Ni}$ and the low sequestration of the metal by gammarids suggest that there is little or no involvement of $\mathrm{Ni}$ in the metabolic functions of these crustaceans. This assumption is consistent with the fact that the essentiality of $\mathrm{Ni}$ remains to be demonstrated in aquatic animals (Muyssen et al., 2004; Chowdhury et al., 2008). 


\subsection{Saturation of metal uptake and binding characteristics}

A linear relationship was obtained between initial $\mathrm{Ni}$ influxes in gammarids and $\mathrm{Ni}$ concentrations in waters below $1000 \mathrm{~g} \mathrm{~L}^{-1}$ (Fig. 2), where the slope corresponded to the uptake rate constant, $k_{u}=0.032 \pm 0.005 \mathrm{~L} \mathrm{~g}^{-1} \mathrm{~d}^{-1}$. This value was within the range reported for other aquatic organisms such as the marine mussel Mytilus galloprovinvialis or the freshwater insect Chaoborus flavicans, for which $k_{u}$ values were 0.047 or $0.019 \mathrm{~L} \mathrm{~g}^{-1} \mathrm{~d}^{-1}$ respectively (Attig et al., 2010; Ponton and Hare, 2010). The uptake rate constant for Ni was 35 times lower than one observed for Cd in G. pulex with $k_{u}=0.46 \mathrm{~L} \mathrm{~g}^{-1} \mathrm{~d}^{-1}$ (Pellet et al., 2009). This difference can be explained by the higher affinities of binding sites for $\mathrm{Cd}$ than for $\mathrm{Ni}$, as described for fish (Niyogi and Wood, 2004).

For the highest exposure concentrations, the metal influx tended to saturate as illustrated by the Figure 2. It was then successfully described by the Michealis-Menten saturation curve (Eq. 6 ), with $I_{\max }=94.0 \pm 1.0 \mu \mathrm{g} \mathrm{g}^{-1} \mathrm{~d}^{-1}$ and $K=2995.5 \pm 108.5 \mu \mathrm{g} \mathrm{L}{ }^{-1}$ (or $\log K=4.7 \mathrm{nM}$ ). In the literature, the affinity of binding sites for the metal is defined by log $K$. By comparison, the log $K$ value is 4.7 for $G$. pulex which is higher than that observed for fish gills with a log $K$ of 4.0 (Niyogi and Wood, 2004). The binding strength of $\mathrm{Ni}$ in this crustacean is thus higher than those reported in fishes. Since $I_{\max }$ depends directly on the density of binding sites for the metal, we calculated the maximal capacity of $G$. pulex to bind the metal as $B_{\max }=746.0 \pm 19.2$ $\mu \mathrm{g} \mathrm{g}^{-1}$ (Borgmann et al, 2004; Norwood et al., 2006). This saturation process confirms that the metal uptake is not constant, but varies with the exposure concentrations. Such decreases in $\mathrm{Ni}$ uptake with increasing $\mathrm{Ni}$ concentrations in waters have also been reported in marine bivalves (Hédouin et al., 2007; Attig et al., 2010).

\subsection{Modelling Ni bioaccumulation at the steady state}

The establishment of $K$ and $B_{\max }$ allowed us to predict the bioaccumulation of $\mathrm{Ni}$ in gammarids at the steady state according to the saturation model (Eq. 8), as presented in Figure 3 . For comparison purposes, we plotted the prediction of the biodynamic model, constructed with the rate constants, $k_{u}$ and $k_{e}$ (Eq. 5). The steady state concentrations of $\mathrm{Ni}$ in gammarids predicted by the biodynamic model were highly correlated with those estimated by Eq. 2 (data given in Table 1), when considering only exposure concentrations below $1000 \mu \mathrm{L} \mathrm{L}^{-1}\left(R^{2}=\right.$ 0.99). The saturation model gave a good prediction of the steady state concentrations for all exposure concentrations $\left(R^{2}=0.99\right)$.

For low exposure concentrations, the prediction of the biodynamic and saturation models is similar with a common linear relationship between $\mathrm{Ni}$ concentrations in gammarids and in waters (Fig. 3). Thus, the slope of this relationship corresponds to the $k_{u} / k_{e}$ or $B_{\max } / K$ ratio, i.e. about $0.25 \mathrm{~L} \mathrm{~g}^{-1}$ (Eq. 5 vs Eq. 8 when $C_{w}<<K$ ). In Hyalella azteca, the $B_{\max } / K$ ratio was $0.70 \mathrm{~L}$ $\mathrm{g}^{-1}$ for $\mathrm{Ni}$, which is in the same order of magnitude than the one observed in G. pulex (Borgmann et al., 2004). Nevertheless, this difference of ratios confirms that the biodynamic kinetics as well as the binding characteristics are specific to each biological species, and that these endpoints need to be established in the laboratory before they can be used as biomonitors (Rainbow, 2002; Borgmann et al., 2004; Worms et al., 2006).

The half-saturation constants were 18.4 and $153.3 \mu \mathrm{g} \mathrm{L}^{-1}$ for $\mathrm{Cu}$ and $\mathrm{Zn}$ in Hyalella azteca (Borgmann et al., 2004). The saturation model is therefore the appropriate model to calculate the bioaccumulation of these essential elements because the saturation process occurs at environmentally-relevant levels of exposure. Since G. pulex has both a high capacity to accumulate $\mathrm{Ni}$ and a half-saturation constant that exceeds $2900 \mu \mathrm{g} \mathrm{L}^{-1}$, the saturation of $\mathrm{Ni}$ bioaccumulation will only occur at very high concentrations $\left(>1 \mathrm{mg} \mathrm{L}^{-1} \mathrm{Ni}\right)$, which correspond to the worst cases of contamination in the environment. Therefore, in most conditions of environmental exposures, the biodynamic and saturation models provide the same prediction of bioavailable $\mathrm{Ni}$ in freshwaters. 


\subsection{Influence of water chemistry on Ni uptake rate}

The $k_{u}$ decreased from 0.032 to $0.013 \mathrm{~L} \mathrm{~g} \mathrm{~g}^{-1} \mathrm{~d}^{-1}$ after Ca concentration was increased from 11.5 to $200 \mathrm{mg} \mathrm{L}^{-1}$ (Fig. 4). This inhibitive effect of Ca on the Ni uptake can be formalized by a model that takes into account the competition of the metal with environmental ligands for the same physiological sites, as described by Bourgeault et al. (2010):

$$
k_{u}=\frac{k_{u \max }}{1+K i_{C a} C_{C a}}
$$

where $K i_{C a}$ is the affinity constant of $\mathrm{Ca}$ for binding sites and $\mathrm{C}_{\mathrm{Ca}}$ is the Ca concentration in water. Fitting the Eq. 9 on the $k_{u}$ dataset obtained by varying the Ca concentrations in waters gave a $k_{\text {umax }}=0.034 \mathrm{~L} \mathrm{~g}^{-1} \mathrm{~d}^{-1}$ and $K i_{C a}=5.51 \mathrm{~L} \mathrm{~g}^{-1}$ or $10^{2.34} \mathrm{M}^{-1}$. Inversely, both $\mathrm{Na}$ and $\mathrm{Mg}$ had no effect on the metal uptake in gammarids under $80 \mathrm{mg} \mathrm{L}^{-1}$ (data not shown). Similarly, a suppressive effect of $\mathrm{Ca}$ on the $\mathrm{Ni}$ uptake has been observed in the crustacean Daphnia magna whereas Na had no effect (Komjarova and Blust, 2009).

Waterborne exposure of $\mathrm{G}$. pulex to $\mathrm{Ni}$ in aquatic microcosms exhibiting various environmentally realistic concentrations of major ions confirms that metal bioaccumulation is influenced by geochemical properties of freshwaters. Increasing the Ca concentration reduces the $\mathrm{Ni}$ uptake, but to a lesser extent than in the case of $\mathrm{Cd}$. Indeed, $K \mathrm{i}_{\mathrm{Ca}}$ was $10^{3.22} \mathrm{M}^{-1}$ during Cd exposures in G. pulex (Pellet et al., 2009). It is known that $\mathrm{Cd}$ interacts with the $\mathrm{Ca}^{2+}$ channels on membranes and consequently competes with $\mathrm{Ca}$ binding sites (Worms et al., 2006; Croteau and Luoma, 2007). It is therefore appropriate to think that Ni behaves, at least to a certain extent, in the same way as Cd. Since varying the concentrations of other major ions such as $\mathrm{Na}$ and $\mathrm{Mg}$ has no effect on $\mathrm{Ni}$ bioaccumulation, Ni uptake does not appear to go through the internalization pathways of $\mathrm{Na}$ and $\mathrm{Mg}$. This is consistent with the fact that $\mathrm{Ni}$ is a respiratory rather than an ionoregulatory toxicant in fish. Indeed, Pane et al. showed that $\mathrm{Ni}$ does not interfere with ionic fluxes at the surface of fish gills, unlike other metals such as $\mathrm{Cu}$, $\mathrm{Zn}$ and Cd, which are known to interact with ion transport sites (Pane et al., 2003 and 2004).

\section{Conclusions}

This study reports for the first time Ni bioaccumulation in G. pulex. Our results strongly suggest that this crustacean can be used as an integrative tool for the quantification of $\mathrm{Ni}$ bioavailability in freshwaters since it is greatly resistant to $\mathrm{Ni}$ and has high accumulation capacities. The investigations into the time course of accumulation and depuration are an important step toward the development of valuable predictive tools. Indeed, they allowed the establishment of kinetic constants and binding characteristics, which are necessary input parameters for the construction of different models characterizing waterborne $\mathrm{Ni}$ bioaccumulation at the steady state. Although the biodynamic and saturation models are comparable for most environmental exposure concentrations in the case of $\mathrm{Ni}$, our results highlight that the choice of the model that should be used depends on both the water's contamination levels and the organism's abilities to regulate the considered metal. We also demonstrated the necessity to take into account some of the water's geochemical properties in the interpretation of $\mathrm{Ni}$ contamination in gammarids. The formalization of the competitive effect of $\mathrm{Ca}$ on $\mathrm{Ni}$ uptake, which can be easily extended to other possible competitors, should allow the improvement of the prediction of $\mathrm{Ni}$ bioavailability in freshwaters by bioaccumulation models. Nevertheless, the organisms can also accumulate metals by dietborne exposure. Further studies are needed to assess the importance of this exposure route for a better interpretation of contamination levels in gammarids. The integration of different exposure 
routes in bioaccumulation models is key to obtaining an environmentally realistic estimation of the metal bioavailability in freshwaters.

\section{Acknowledgments}

The authors wish to thank both the ONEMA (Office National de l'Eau et des Milieux Aquatiques) and the Région Ile-de-France for their financial support. We are grateful to J. Guieu for his services as English editor.

\section{References}

Ahearn, G.A., Mandal, P.K., Mandal, A., 2004. Mechanisms of heavy-metal sequestration and detoxification in crustaceans: a review. J. Comp. Physiol. 174(B), 439-452.

Attig, H., Dagnino, A., Negri, A., Jebali, J., Boussetta, H., Viarengo, A., Dondero, F., Banni, M., 2010. Uptake and biochemical responses of mussels Mytilus galloprovinvialis exposed to sublethal nickel concentrations. Ecotox. Environ. Safety 73, 1712-1719.

Besser, J.M., Brumbaugh, W.G., Brunson, E.L., Ingersoll, C.G., 2005. Acute and chronic toxicity in water and diet to the amphipod Hyalella azteca. Environ. Toxicol. Chem. 24, 18071815.

Bourgeault, A., Gourlay-Francé, C., Tusseau-Vuillemun, M.H., 2010. Modeling the effect of water chemistry on the bioaccumulation of waterborne cadmium in zebra mussels. Environ. Toxicol. Chem. 29, 2182-2189.

Borgmann, U., Norwood, W.P., Dixon, D.G., 2004. Re-evaluation of metal bioaccumulation and chronic toxicity in Hyalella azteca using saturation curves and the biotic ligand model. Environ. Poll. 131, 469-484.

Buchwalter, D.B., Luoma, S.N., 2005. Differences in dissolved cadmium and zinc uptake among stream insects: Mechanistic explanations. Environ. Sci. Technol. 39, 498-504.

Chowdhury, M.J., Bucking, C., Wood, C.M., 2008. Pre-exposure to waterborne nickel downregulates gastrointestinal nickel uptake in rainbow trout: indirect evidence of nickel essentiality. Environ. Sci. Technol. 42, 1359-1364.

Clason, B., Langston, W.J., Zauke, G.P., 2004. Bioaccumulation of trace metals in the amphipod Chaetogammarus marinus (Leach, 1815) from the Avon and Tamar estuaries (UK): comparison of two-compartment and hyperbolic toxicokinetics models. Mar. Environ. Res. 57, 171-195.

Croteau, M.N., Luoma, S.N., 2007. Characterizing dissolved Cu and Cd uptake in terms of the biotic ligand and biodynamics using enriched stable isotopes. Environ. Sci. Technol. 41, 31403145.

Dedourge-Geffard, O., Palais, F., Biagianti-Risbourg, S., Geffard, O., Geffard, A., 2009. Effects of metals on feeding rate and digestive enzymes in Gammarus fossarum: An in situ experiment. Chemosphere 77, 1569-1576.

Directive 2008/105/EC of the European Parliament and the Council of the European Union for environmental quality standards in the field of water policy (WFD). Official Journal of European Communities.

Felten, V., Charmantier, G., Mons, R., Geffard, A., Rousselle, P., Coquery, M., Garric, J., Geffard, O., 2008. Physiological and behavioural responses of Gammarus pulex (Crustacea: Amphipoda) exposed to cadmium. Aquat. Toxicol. 86, 413-425.

Ferreira, D., Ciffroy, P., Tusseau-Vuillemin, M.H., Garnier, C., Garnier, J.M., 2009. Modelling exchange kinetics of copper at the water-aquatic moss (Fontinalis antipyretica) interface: Influence of water cationic composition ( $\mathrm{Ca}, \mathrm{Mg}, \mathrm{Na}$ and $\mathrm{pH}$ ). Chemosphere 74, 1117-1124.

Gaillardet, J., Viers, J., Dupré, B., 2004. Trace elements in river waters. in: Holland, H.D., Turekian, K.K. (Eds.), Treatise on geochemistry: Surface and ground water, weathering, and soils. Elsevier, Amsterdam, pp. 225-272. 
Geffard, A., Sartelet, H., Garric, J., Biagianti-Risbourg, S., Delahaut, L., Geffard, O., 2010. Subcellular compartmentalization of cadmium, nickel, and lead in Gammarus fossarum: Comparison of methods. Chemosphere 78, 822-829.

Hédouin, L., Pringault, O., Metian, M., Bustamante, P., Warnau, M., 2007. Nickel bioaccumulation in bivalves from the New Caledonia lagoon: Seawater and food exposure. Chemosphere 66, 1449-1457.

Keithly, J., Brooker, J.A., DeForest, D.K., Wu, B.K., Brix, K.V., 2004. Acute and chronic toxicity of nickel to a cladoceran (Ceriodaphnia dubia) and an amphipod (Hyalella azteca). Environ. Toxicol. Chem. 23, 691-696.

Kienle, C., Köhler, H.R., Gerhardt, A., 2009. Behavioural and development toxicity of chlorpyrifos and nickel chloride to zebrafish (Danio rerio) embryos and larvae. Ecotoxicol. Environ. Safety 72, 1740-1747.

Komjarova, I., Blust, R., 2009. Effect of $\mathrm{Na}, \mathrm{Ca}$ and $\mathrm{pH}$ on simultaneous uptake of $\mathrm{Cd}, \mathrm{Cu}, \mathrm{Ni}$, $\mathrm{Pb}$, and $\mathrm{Zn}$ in the water flea Daphnia magna measured using stable istopes. Aquat. Toxicol. 94, 81-86.

Kozlova, T., Wood, C.M., McGeer, J.C., 2009. The effect of water chemistry on the acute toxicity of nickel to the cladoceran Daphnia pulex and the development of a biotic ligand model. Aquat. Toxicol. 91, 221-228.

Liu, X.J., Ni, I.H., Wang, W.X., 2002. Trophic transfer of heavy metals from freshwater zooplankton Daphnia magna to zebrafish Danio reiro. Wat. Res. 36, 4563-4569.

Luoma, S.N., Rainbow, P.S., 2005. Why is metal bioaccumulation so variable? Biodynamics as a unifying concept. Environ. Sci. Technol. 39, 1921-1931.

McGeer, J.C., Brix, K.V., Skeaff, J.M., DeForest, D.K., Brigham, S.I., Adams, W.J., Green, A., 2003. Inverse relationship between biocentration factor and exposure concentration for metals: implications for hazard assessment of metals in the aquatic environment. Environ. Toxicol. Chem. 22, 1017-1037.

Muyssen, B.T.A., Brix, K.V., DeForest, D.K., Janssen, C.R., 2004. Nickel essentialty and homeostasis in aquatic organisms. Environ. Rev. 12, 113-137.

Niyogi, S., Wood, C.M., 2004. Biotic ligand model, a flexible tool for developing site-specific water quality guidelines for metals. Environ. Sci. Technol. 23, 6177-6192.

Norwood, W.P., Borgmann, U., Dixon, D.G., 2006. Saturation models of arsenic, cobalt, chromium and manganese bioaccumulation by Hyalella azteca. Environ. Poll. 143, 519-528.

Pane, E.F., Richards, J.G., Wood, C.M., 2003. Acute waterborne nickel toxicity in the rainbow trout (Oncorhynchus mykiss) occurs by a respiratory rather than ionoregulatory mechanism.

Aquat. Toxicol. 63, 65-82.

Pane, E.F., Haque, A., Wood, C.M., 2004. Mechanistic analysis of acute, Ni-induced respiratory toxicity in the rainbow trout (Oncorhynchus mykiss): an exclusively branchial phenomenon. Aquat. Toxicol. 69, 11-24.

Pellet, B., Geffard, O., Lacour, C., Kermoal, T., Gourlay-Francé, C., Tusseau-Vuillemin, M.H., 2009. A model predicting waterborne cadmium bioaccumulation in Gammarus pulex: the effects of dissolved organic ligands, calcium, and temperature. Environ. Toxicol. Chem. 28, 2434-3442.

Ponton, D.E., Hare, L., 2010. Nickel dynamics in the lakewater metal biomonitor Chaoborus. Aquat. Toxicol. 96, 37-43.

Rainbow, P.S., 2002. Trace metal concentrations in aquatic invertebrates: why and so what? Environ. Pollu. 120, 497-507.

Rainbow, P.S., 2007. Trace metal bioaccumulation: Models, metabolic availability and toxicity. Environ. Internat. 33, 576-582.

Worms, I., Simon, D.F., Hassler, C.S., Wilkinson, K.J., 2006. Bioavailability of trace metals to aquatic microorganisms: importance of chemical, biological and physical processes on biouptake. Biochimie 88, 1721-1731.

Xu, Q., Pascoe, D., 1993. The bioconcentration of zinc by Gammarus pulex (L.) and the application of a kinetic model to determine bioconcentration factors. Wat. Res. 27, 1683-1688. 
Table 1. Initial influxes (I), steady state $\mathrm{Ni}$ concentrations $\left(C_{s s}\right)$ and elimination rate constants $\left(k_{e}\right)$ calculated from kinetic models of $\mathrm{Ni}$ accumulation (Eq. 2) or depuration (Eq. 4) during exposure of Gammarus pulex to various Ni concentrations in water.

\begin{tabular}{|c|c|c|c|c|c|c|c|c|}
\hline \multirow{3}{*}{$\frac{[\mathrm{Ni}]_{\text {water }}\left(\mu \mathrm{g} \mathrm{L}^{-1}\right)}{5}$} & \multicolumn{6}{|c|}{ Accumulation } & \multirow{2}{*}{\multicolumn{2}{|c|}{$\begin{array}{c}\text { Depuration } \\
k_{\text {e-dep }}\left(\mathrm{d}^{-1}\right) \\
\end{array}$}} \\
\hline & \multicolumn{2}{|c|}{$I\left(\mu \mathrm{g} \mathrm{g}^{-1} \mathrm{~d}^{-1}\right)$} & \multicolumn{2}{|c|}{$C_{s s}\left(\mu \mathrm{g} \mathrm{g}^{-1}\right)$} & \multicolumn{2}{|c|}{$k_{e-a c c}\left(d^{-1}\right)$} & & \\
\hline & 0.17 & 0.06 & 1.4 & 0.2 & 0.187 & 0.036 & 0.095 & 0.016 \\
\hline 10 & 0.40 & 0.21 & 2.8 & 0.8 & 0.144 & 0.057 & 0.094 & 0.060 \\
\hline 100 & 3.62 & 1.20 & 25.6 & 7.6 & 0.139 & 0.110 & 0.216 & 0.023 \\
\hline 1000 & 22.50 & 4.85 & 194.7 & 74.8 & 0.114 & 0.056 & 0.107 & 0.059 \\
\hline 10000 & 69.59 & 5.99 & 581.5 & 86.0 & 0.119 & 0.023 & 0.162 & 0.050 \\
\hline 100000 & 90.05 & 17.50 & 723.5 & 235.3 & 0.124 & 0.052 & 0.084 & 0.004 \\
\hline Mean & & & & & 0.138 & 0.027 & 0.126 & 0.052 \\
\hline
\end{tabular}

Values in italics are standard errors 


\section{Figures}

Figure 1. Time course of net accumulation (A) and depuration (B) in Gammarus pulex exposed to $0.1 \mathrm{mg} \mathrm{L}^{-1} \mathrm{Ni}$ in water. Curves represent the best fits of data to the first-order kinetic models of accumulation (Eq. $2 ; R^{2}=0.88$ ) or depuration (Eq. $4 ; R^{2}=0.92$ ); with $n=5$ exposed individuals for each symbol.
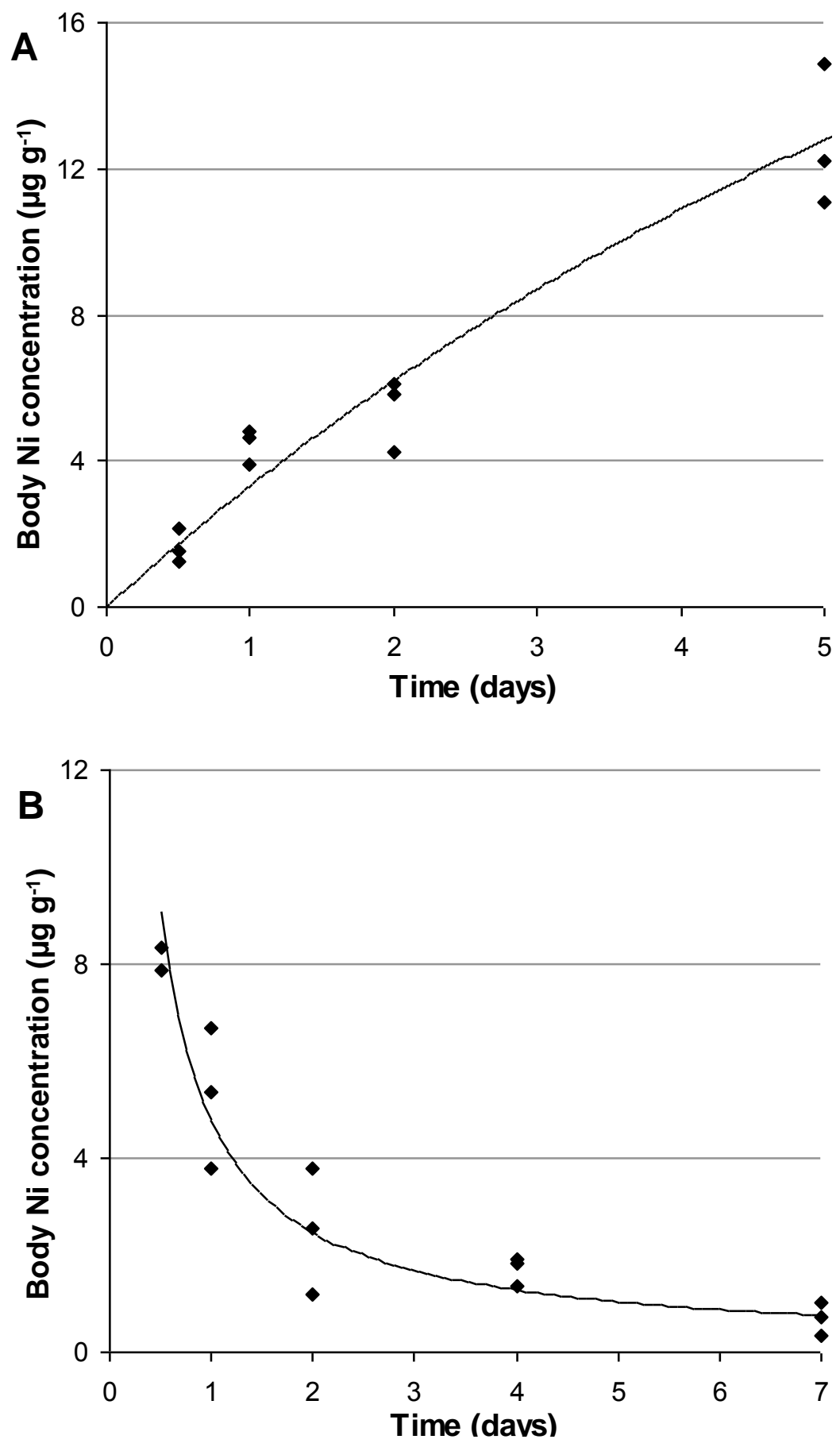
Figure 2. Metal influx in Gammarus pulex exposed to different $\mathrm{Ni}$ concentrations in water. The curve represents the best fit of data to the Michaelis-Menten equation (Eq. 3; $R^{2}=0.99$ ). Symbols are means of 3 pools of 5 exposed individuals ( \pm standard errors).

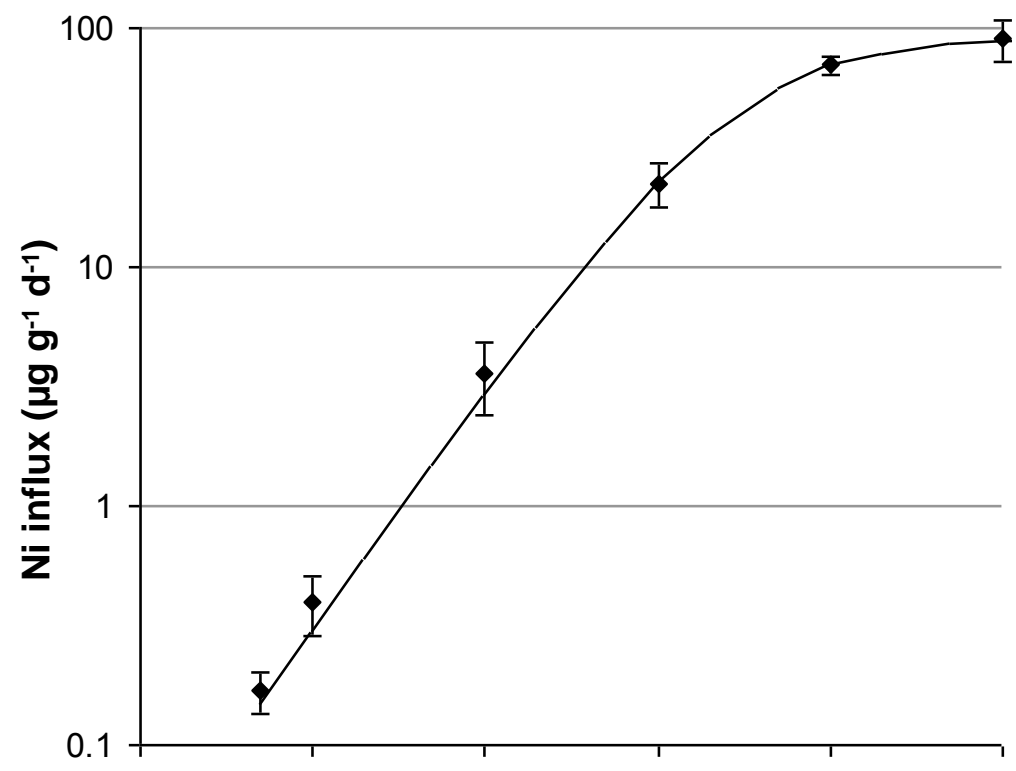

Figure 3. Steady state Ni concentrations in Gammarus pulex predicted by the biodynamic $(--)$ and saturation (-) models. Symbols are means \pm SE of steady state Ni concentrations $\left(C_{s s}\right)$ estimated by Eq. 2 for each exposure concentration (Table 1$)$.

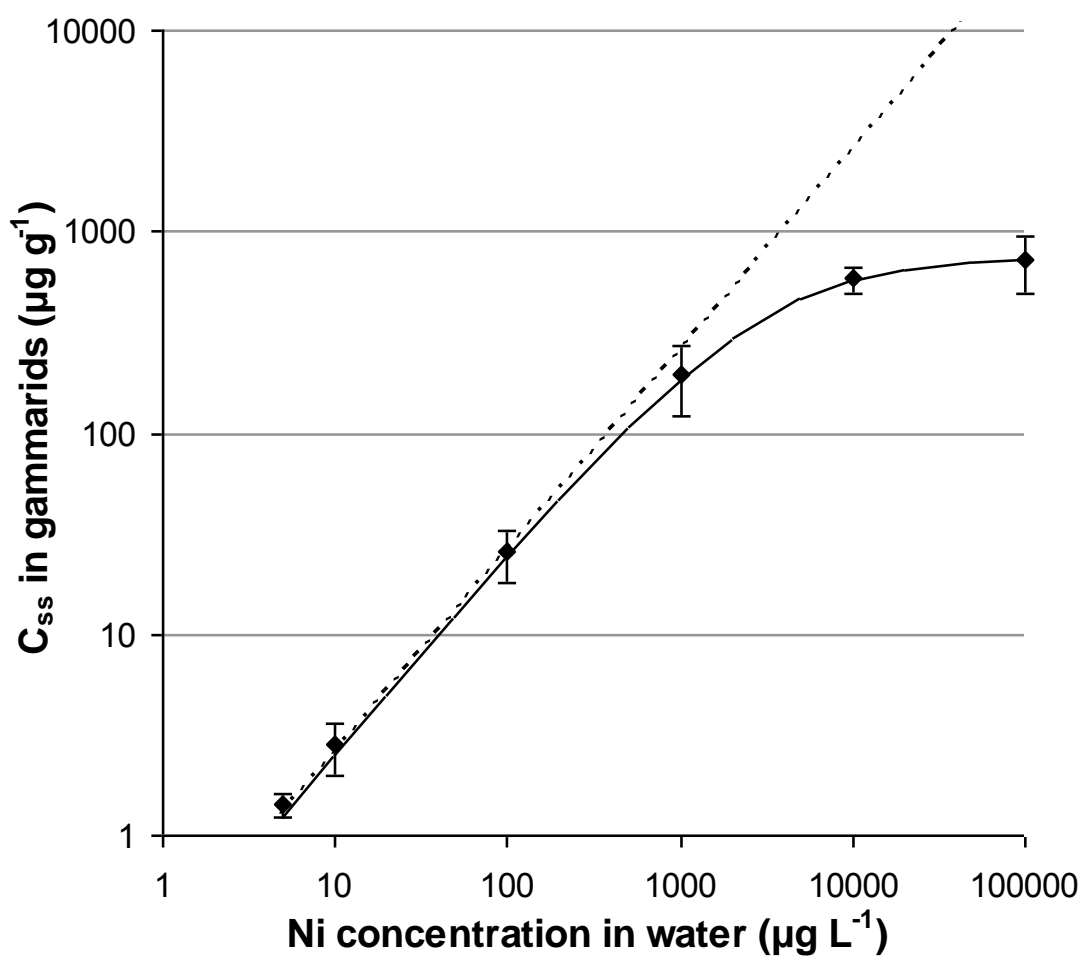


Figure 4. Inhibition of the $\mathrm{Ni}$ uptake rate by increasing $\mathrm{Ca}^{2+}$ concentrations in Gammarus pulex exposed to $0.1 \mathrm{mg} \mathrm{L}^{-1} \mathrm{Ni}$. The curve is the best fit of data to a competitive model (Eq. $9 ; R^{2}=0.95$ ). Symbols are means of 3 pools of 5 exposed individuals ( \pm standard errors).

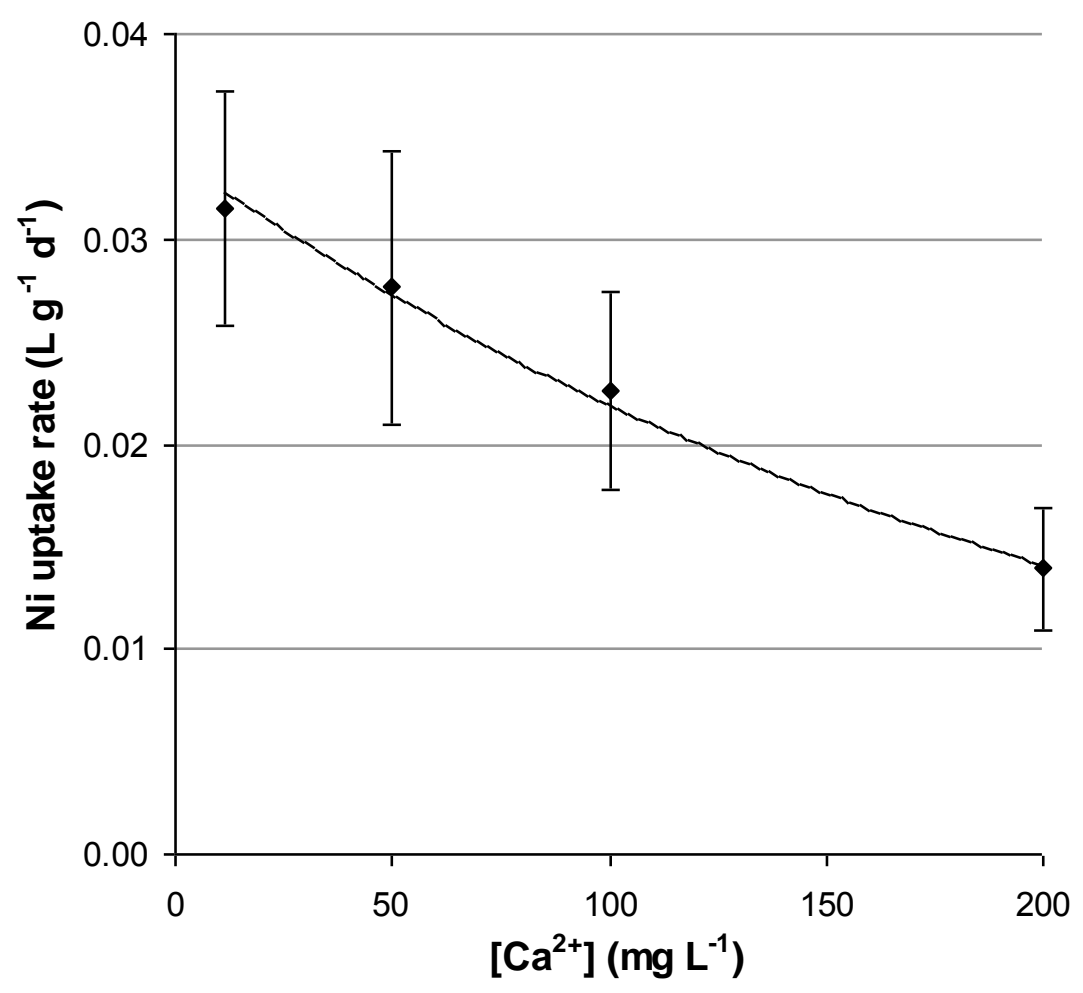

